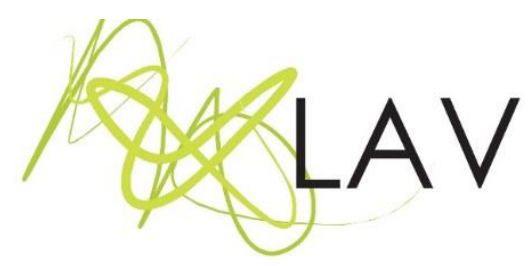

\title{
Os desenhos de uma criança da Escolinha de Arte do Recife: o olhar artístico em meio às imagens cinematográficas e às séries televisivas
}

The drawings of a child at the Art School of Recife: the artistic look amid cinematographic images and television series

\author{
Maísa Gomes Sobrali \\ Universidade Federal de Pernambuco \\ Márcia Regina Barbosaii \\ Universidade Federal de Pernambuco
}

\begin{abstract}
Resumo
Este estudo objetivou compreender como a criança significa os desenhos criados por ela a partir da visualidade de imagens de filmes e de séries televisivas; identificar quais as imagens que a motivaram para a criação dos desenhos e analisar as histórias e os significados que a criança atribui aos desenhos. Neste intento, cinco desenhos produzidos pela criança e os dados da entrevista foram trabalhados com base na análise de conteúdo (FRANCO, 2008). Os resultados revelaram que a criança significa os desenhos a partir de imagens da própria história, por isso, em atenção aos resultados pode ser ressaltado que a história de vida da criança figura como um contributo no compartilhamento de conhecimentos.
\end{abstract}

Palavras-chave: Desenhos infantis, imagens cinematográficas, séries televisivas.

\begin{abstract}
This study aimed to understand how the child gives meaning to the drawings created by her from the visuality of filmic and television series images, identify which images motivated her in the drawing creation, and analyze the stories and meanings the child attributes to the drawings. In this attempt, five drawings created by the child together with the data collected in the interview were analyzed according to the theory of Content Analysis (FRANCO, 2008). The results revealed that the child attributes meaning to the drawings from images of her own history; therefore, what can be emphasized is that the background of the child figures as a contribution to knowledge sharing.
\end{abstract}

Keywords: Children drawings, cinematographic images, television series.

\section{Introdução}

As Artes constituem-se em saberes imbricados em subjetividades que criam, recriam e compartilham conhecimentos. Assim, entende-se ser pertinente a discussão sobre o desenho infantil como elaboração criativa que ganha relevância a partir do olhar da criança perante o mundo. Esse olhar da criança ganha corpo neste artigo a partir das significações que imagens cinematográficas e episódios de séries televisivas podem

Revista Digital do LAV - Santa Maria - vol. 10, n. 3, p. 73-97 - set./dez. 2017 ISSN 1983 - 7348

http://dx.doi.org/10.5902/1983734828861 
possuir para a mesma, quando essas imagens são representadas através de desenhos.

Neste estudo, a criança é a protagonista. Ela cria e recria a própria história através dos próprios desenhos, ou seja, ela está em diálogo com o meio em que ela vive. Isto ressalta a afirmação de Geertz ao declarar que "somos todos afetados pelos costumes de nosso próprio tempo e lugar" (GEERTZ apud WILSON e WILSON, 2011, p. 60). Essa relação temporal e espacial foi fator relevante para o desenvolvimento dessa pesquisa, sabendo que novas histórias são contadas através dos desenhos realizados pelas crianças.

As histórias contadas através do desenho infantil bebem do que a criança imagina, do que ela vê, de como ela pensa e age nos espaços que habita. As imagens cinematográficas e as séries de TV estão disponíveis através da televisão, já que, conforme Edith Derdyk (1994, p. 53) "a TV traz tudo para você". No entanto, atualmente, celulares, tablets e computadores também são dispositivos que transmitem filmes e séries para as crianças, esses que atraem diversos espectadores por existirem em variedade de gêneros.

Em diálogo com os argumentos citados acima, o objetivo central que norteou essa pesquisa consiste em compreender como a criança significa os desenhos criados por ela através da visualidade de imagens cinematográficas e de séries televisivas. Os objetivos específicos, centraram-se em identificar as imagens que motivaram a criança a criar os desenhos; e, analisar as histórias e os significados que a criança atribui aos desenhos.

Foi realizado o mapeamento dos trabalhos feitos em torno dos últimos dez anos, de 2007 a 2017 nos sites Periódicos CAPES e Scielo. A busca foi feita através das palavras-chave específicas que deveriam estar no título dos trabalhos: desenho infantil ou desenho da criança. Os trabalhos selecionados abrangem as Ciências Humanas. Através da filtragem, nos sites da CAPES e Scielo foram identificados cinco artigos; alguns deles, em ambos os sites, tratam de desenhos feitos por crianças surdas, em que os desenhos são identificados como uma forma de comunicação. 
Um dos trabalhos que abrangem outras perspectivas e está no site Scielo e Periódicos CAPES é o artigo intitulado "O self dialógico no desenho infantil" das autoras Nadja Silva e Angelina Vasconcelos (2013), trata-se de um trabalho focado na Psicologia, que se fundamenta em pressupostos de Vigotski, Bakhtin e Hermans na análise dos desenhos a partir das falas de crianças entre um e seis meses e três anos, numa relação entre a fala e ação da criança.

Em contrapartida, alguns dos trabalhos encontrados nos sites supracitados, dialogam com filmes e com séries de TV, sendo o campo de pesquisa a Escolinha de Arte do Recife (EAR), sociedade civil sem fins lucrativos, que surge como um desdobramento do Movimento Escolinhas de Arte (MEA). Sobre a EAR e nos ditos da professora Maria Betânia e Silva et al (2013, p. 49), a escolinha de Arte do Recife introduziu desde 1953 "uma linha de ação metodológica inovadora valorizando o potencial criativo de seus alunos na perspectiva da realidade sociocultural vivenciada pelos mesmos".

Destarte, este artigo não foca o desenho enquanto criação que contribui ou dialoga com o desenvolvimento das capacidades cognitivas da criança. Aqui o desenho infantil se manifesta como elemento permeado de sensibilidade em meio à interação da criança com o cenário cultural e histórico que ela constrói e interage.

\section{Arte como livre expressão, arte como técnica e arte como atividade: o desenho da criança é uma arte?}

O próprio ato de criar pode fornecer-lhe novos vislumbres, novas perspectivas e nova compreensão para a ação futura (LOWENFELD e BRITTAIN, 1977, p. 16).

A criança é um sujeito criador e com saberes não dissociados da história de vida dela, o que ela vive e sabe é mola propulsora para as próprias criações. Entre essas criações, neste trabalho interessa o desenho gráfico na perspectiva de que ele possui valor social e que a partir de Lowenfeld e Brittain (1977, p. 45) "o desenho pode, assim, tornar-se uma ampliação do eu no mundo da realidade" (LOWENFELD e BRITTAIN, 1977, p. 45).

Viktor Lowenfeld é considerado por dez professores em Arte Educação em universidades americanas, o mais influente arte educador do século $\mathrm{XX}$, conforme Barbosa (2015); "e foi tão importante para a Arte Educação no mundo: o mais importante modernista do ensino da arte" (BARBOSA, 2015, p. 447). O pensamento 
do arte educador Lowenfeld sobre a capacidade criadora da criança, dialogou com as exposições infantis modernistas do século XX no Brasil.

O valor da livre expressão no desenho da criança é uma atribuição modernista que não foi rapidamente aceita no Brasil; conforme a arte educadora Ana Mae Barbosa (2010, p. 31) a preparação para as ideias modernistas foi tímida e elas eclodiram em 1922. Foram exposições de arte infantil que proporcionaram a aceitação pelo público da arte espontânea "expressionista".

Ana Mae Barbosa (2015) problematiza o ensino das Artes Visuais perpassando pelas diferentes perspectivas histórias que caracterizam esse ensino no Brasil. Barbosa faz leituras das perspectivas temporais: arte como técnica; arte como atividade; arte como livre expressão; e, arte como conhecimento. E, essa temporalidade importa para o estudo que se concretiza neste artigo, no entendimento de quê as perspectivas que os grupos sociais atuais têm sobre o desenho da criança derivam de um marco histórico abrangente.

Conforme Barbosa (2010) no século XIX as Artes tinham o teor científico de serem voltadas para o trabalho, e, essa cientificização da arte continuou nas primeiras décadas do século $X X$ regendo o ensino da arte na escola primária e secundária. $O$ Ensino do Desenho (ensino da arte) objetivava a formação para as demandas econômicas do Brasil, o que era coerente com os ideais dos liberais e dos positivistas.

O ensino da arte descontextualizado do ler, fazer e contextualizar a obra de arte, está presente nas concepções de arte como técnica e arte como atividade. Sobre isso, é cabível fazer referência à Lei no 5.692/71, porque conforme Silva (2005, p.58) "a partir dessa Lei, o ensino da arte no Brasil passou a ser designado de Educação Artística". Nos ditos de Barbosa (2005, p. 12) "a educação artística é concebida como uma atividade, mas não como uma disciplina". E, estando no contexto da arte como uma atividade, a mesma fazia parte do componente curricular em que os alunos não precisavam de nota. Além, de ser marcada pelas imagens ruins dos livros didáticos, as imagens das folhas de colorir e pela falta de experiência estética.

Enfim, as concepções de arte como técnica e de arte como atividade, não dialogam com a ideia da arte da criança, livre de amarras sociais e em diálogo com culturas, em que este artigo caminha para analisar. A partir da concepção de arte pós- 
moderna, as ideias que seguem contribuirão para apreciar a questão que este trabalho objetiva responder.

\section{Do Movimento Modernista ao Movimento Pós-modernista: olhares para o desenho infantil}

O Movimento Modernista ganha corpo no Brasil através da atuação de vários artistas e intelectuais como Anita Malfatti, Mário de Andrade, Herbert Read, Viktor Lowenfeld, entre outros. O modernismo impulsionou a criação da Escolinha de Arte do Brasil $(E A B)$, no Rio de Janeiro, e, o Movimento Escolinhas de Arte (MEA), este que surgiu através da criação da EAB.

A filosofia da Escolinha de Arte do Brasil está relacionada com a proposta modernista de prezar pela livre expressão. Para o modernismo, todas as pessoas são capazes de criar. O Modernismo garantiu que o exercício da arte é importante para o crescimento da habilidade criativa que todos nós temos em diversos potenciais (BARBOSA, 2015).

A arte educadora Noêmia Varela, em entrevista para Fernando de Azevedo em 1998, contou sobre a experiência dela ao visitar a Escolinha de Arte do Brasil. Noêmia diz:

Lúcia $[\ldots]$ que trabalhava com os alunos. Augusto me recebeu e falou sobre arte/educação, a história da escolinha e de Herbert Read. [...] [Augusto Rodrigues] já estava imbuído das ideias e da importância da arte no processo da educação, visão que me deixou encantada (VARELA apud AZEVEDO, 2011, p. 231).

Noêmia Varela foi uma das fundadoras da Escolinha de Arte do Recife em 1953 (EAR). A EAR foi um desdobramento do Movimento Escolinhas de Arte (MEA). Conforme Azevedo (2011, p. 223), Noêmia Varela defendeu o MEA: "por seu valor libertário e suas bases teóricas em Herbert Read e Viktor Lowenfeld".

Portanto, a partir do que foi abordado até aqui, é pertinente dizer que o Movimento Modernista foi fundamental para a criação do MEA. O MEA continua atuante através das escolinhas de arte que existem em alguns Estados do Brasil. Desenhos de crianças, especificamente, os produzidos na Escolinha de Arte do Recife, têm expressado a visão de mundo e os sentimentos delas sobre o período em que vivem.

Brent Wilson e Marjorie Wilson (2011, p. 60) compartilham a ideia que somos afetados pelos costumes do nosso tempo e lugar e abordam sobre o desenho da 
criança a partir de um viés pós-modernista, pois eles estão vinculados a uma abordagem americana denominada por Arte/Educação entendida como uma disciplina - DBAE (RIZZI, 2011). A visão pós-modernista no ensino da arte sinaliza um rompimento com a ideia de arte como livre-expressão do Movimento Modernista:

A visão mais contemporânea no ensino da arte, na qual o DBAE se insere, valoriza por sua vez a construção e a elaboração como procedimento artístico, enfatiza a cognição relativa à emoção e procura acrescentar à dimensão do fazer artístico a possibilidade de acesso e compreensão do patrimônio cultural da humanidade (RIZZI, 2011, p. 337).

A partir dessa visão, entende-se que o fazer artístico da criança não se desloca dos espaços socioculturais que ela transita, e, das vivências artísticas da mesma, como a visitação em museus, teatros, cinemas, entre outros espaços que motivam a criança a ler, a produzir e a contextualizar objetos artísticos. E, é o desenho da criança um objeto artístico movido pelas imagens que a mesma vê e interage. Baseados, também nessa ideia, Brent W. e Marjorie W. (2011, p. 60) lançam o questionamento: "Como podemos deixar de ver a forte influência da ilustração e da fotografia no desenho de crianças? "

Os autores citados no parágrafo anterior, lançam a partir de argumentos uma quebra com a ideia de florescimento natural na arte das crianças e dizem que elas são influenciadas por imagens e ideias de fazer arte. Eles referem-se aos desenhos gráficos através da expressão "signos configuracionais", como segue o argumento dos mesmos:

A criança aprende a formar seus próprios signos configuracionais principalmente por meio da observação-defazer-signos-configuracionais de outras pessoas, verificando, então, a maneira pela qual são feitos, as razões pelas quais são feitos, (...) e as diversas formas que tais signos tomam em nossa cultura (WILSON e WILSON, 2011, p. 63).

Nesse sentido, os desenhos são produções culturais que fazem referência às relações entre as pessoas e os elementos da cultura; eles são signos configuracionais que transitam de geração a geração. Desenhar é uma tarefa complexa, e, a partir de argumentos da artista plástica e autora Edith Derdyk (1994, p. 26), a concepção de desenho pode ser ampliada a partir da memória individual e coletiva, "a fim de fazer uma revisão dos caminhos do desenho na história do homem". 
Em pleno século XXI, a tecnologia audiovisual está muito presente na vida de várias pessoas, assim como ela contribui na formação das ideias e nos comportamentos das pessoas. Específicas imagens visualizadas em telas podem ser as imagens escolhidas por crianças para serem representadas em forma de desenhos. O argumento de Lowenfeld e Brittain (1977, p. 58) de que a criança mostra o que é importante para ela ao fazer o desenho, ou seja, através das escolhas temáticas, revela que a criança de fato realiza uma seleção a partir do todo que está disponível para ela.

A TV traz tudo pra você. O imaginário contemporâneo é entregue a domicílio. A criança é submetida a um profundo condicionamento cultural, e é sobre estes conteúdos que a criança vai operar. A ilustração, o desenho animado, a história em quadrinhos, $[. .$.$] são representações que se tornam quase$ realidade (DERDYK, 1994, p. 53).

Enfim, a televisão é refletora de imagens, e, um aparelho que, em certa medida, proporciona a imaginação através de variadas programações como os desenhos animados, filmes, entre outros. E, sabendo que há a seleção de imagens para serem representadas através de desenhos pelo público infantil, se torna relevante compreender como a criança significa os desenhos criados por ela através da visualidade de imagens cinematográficas e de séries televisivas.

\section{Imagens cinematográficas e de séries televisivas e suas significações no desenho gráfico infantil}

O cinema, produção tecnológica e cultural, está presente na vida de pessoas através de diversos recursos tecnológicos e se faz presente na vida de quem trabalha na produção de filmes. As produções cinematográficas variam entre gêneros, correspondendo assim às específicas preferências do público-espectador. A autora Monica Fantin menciona o cinema "como arte do século XX" e continua:

o cinema se faz de paixões públicas e envolve a vida cotidiana em diversos aspectos, pois o cinema é um fenômeno de exposição pública só superado - em certos aspectos e sob certos ângulos - apenas pela televisão. Este é um dos fatores da constituição desta cultura e a constante identificação e confusão entre filme e cultura do cinema (FANTIN, 2006, p. 102).

Através das palavras de Fantin, percebe-se que a televisão tem um elevado alcance em comparação ao cinema. No Brasil, país perpassado por desigualdades sociais, 
nem todas as pessoas tem acesso ao cinema ou podem frequentar o cinema, porém, ter acesso à televisão pode significar ter acesso a imagens cinematográficas e, ainda, a episódios seriados. É pertinente essa discussão para evidenciar uma popularidade no acesso aos filmes e as séries televisivas através da televisão.

Historicamente, vários pesquisadores teorizaram sobre o cinema a partir de variados estudos, e, atualmente, diversas pessoas continuam a estudar a arte cinematográfica. Entre os estudiosos, o Graeme Turner apresenta o cinema como "uma prática social inserida no funcionamento da própria cultura, requerendo atenção às suas dimensões de produção, consumo, prazer e significação" (FANTIN, 2006, p. 103).

Em detrimento à significação atribuída por pessoas aos filmes, possivelmente, isso decorre da relevância da relação entre filme-espectador, e para explicar como essa relação se estrutura, consoante Ismail Xavier apud Fantin (2006, p. 100) "implica uma tentativa de caracterizar, discutir e avaliar o tipo de experiência audiovisual que o cinema oferece". Outra questão para ser pensada e que foi levantada pelo crítico de arte francês Jacques Aumont (2002, p. 81) é: "por que e como se olha uma imagem?" Para transpor a resposta em termos mais psicológicos, Aumont formula a seguinte hipótese a partir da linha de E. H. Gombrich: "a imagem tem por função primeira garantir, reforçar, reafirmar e explicar nossa relação com o mundo visual [...]" (AUMONT, 2002, p. 81).

A imagem, para além de ser as de filmes ou de episódios seriados, pode ser um desenho gráfico, uma arquitetura, uma pintura, etc. E, a imagem "desempenha papel de descoberta do visual" retomando a hipótese levantada por Aumont (2002, p. 81). A ideia de descoberta do visual dialoga com a maneira da pessoa ver, pensar e agir nos espaços que habita, o contato social provoca o uso da imaginação, da ilusão, da invenção, do raciocínio, etc. Nesse sentido, cada pessoa é subjetivada perante as imagens do mundo real, assim como perante as imagens fictícias.

Em relação ao acesso às imagens de séries televisivas, isso pode acontecer através da televisão, de computadores e de dispositivos móveis. Pode-se dizer que as séries de TV possuem características que dialogam com características de filmes. $\mathrm{O}$ autor Marcel Vieira Silva discorre sobre isso dizendo que: 


\begin{abstract}
A arte das séries de TV, como bem aponta Colonna (2010), estaria definida não unicamente pela contenção da linguagem e pelo investimento em mise-en-scène (categorias valorativas tipicamente cinematográficas), mas, sobretudo pelo texto, capaz de atrair a atenção do público em um meio de exibição, por excelência, dispersivo e cacofônico (o aparelho de TV ou mesmo a tela do computador, sem o efeito imersivo da sala escura de cinema [...]) (SILVA, 2014, p. 245).
\end{abstract}

Silva (2014) também argumenta que a série televisiva repousa no retorno de personagens, de temas e de situações. Ou seja, existe uma continuidade intrínseca no movimento de novidades que a série de televisão é capaz de gerar. Provavelmente, esse enredo de continuidades através dos episódios das séries de TV gera expectativas e prazer na criança que as assistem, e esse fator pode ser motivador para que ela crie desenhos.

Destarte, é relevante destacar que, independentemente de imagens serem visualizadas em filmes ou séries de televisão, a criança escolhe para desenhar as imagens as quais ela se identifica, assim como os personagens e os elementos que ela deseja desenhar e que se encontram de forma ativa na mente dela, em concordância com Lowenfeld e Brittain (1977).

Enfim, a criança atribui significações às imagens cinematográficas e as de série televisivas a partir da interioridade dela, o que está intrinsecamente relacionado com a interação dela com as pessoas e com os espaços. Portanto, as significações que imagens podem possuir correspondem às singularidades de casos, assim como, as sensibilidades intrínsecas em cada singularidade.

\title{
Procedimentos metodológicos
}

Esta pesquisa de abordagem qualitativa objetivou responder "Como a criança significa os desenhos criados por ela através da visualidade de imagens cinematográficas e de séries televisivas"? Para tanto, foram estudados desenhos gráficos de uma criança. É pertinente considerar que, conforme os autores Mazzotti e Gewandsznajder (2001, p. 147): "as investigações qualitativas, por sua diversidade e flexibilidade, não admitem regras precisas, aplicáveis a uma gama de casos".

O campo para contemplar o problema em questão foi a Escolinha de Arte do Recife, que está localizada em Recife/PE, na Rua do Cupim, no Bairro das Graças. Foram analisados cinco desenhos infantis produzidos em 2017 por uma criança de 11 anos. A escolha da idade está relacionada à faixa etária, 09 a 12 anos, que Lowenfeld 
(1976), Lowenfeld e Brittain (1977) chamam atenção como sendo a fase do desenvolvimento do desenho, denominada de figuração realista.

Para conhecer os motivos da criança para a realização dos desenhos foram associados à análise documental, a concretização de entrevista estruturada, levando em consideração o que Mazzotti e Gewandsznajder (2001, p. 169) dizem: "A análise de documentos $[\ldots]$ pode ser combinada com outras técnicas de coleta, $[\ldots]$ ". $E$, Fraser e Gondim (2004, p. 144) dizem que as entrevistas estruturadas podem apoiarse "[...], ou em um roteiro fixo contendo perguntas objetivas que permitam respostas abertas a serem submetidas posteriormente a técnicas de análise de conteúdo [...]".

As falas da criança sobre os desenhos dela no decorrer da entrevista foram trabalhadas com base na análise de conteúdo, que conforme Franco (2008, p. 16) "[...] toda análise de conteúdo implica comparações contextuais. Os tipos de comparações podem ser multivariadas". E, o autor pondera que o que está escrito, falado, mapeado, figurativamente desenhado, "[...] sempre será o ponto de partida para a identificação do conteúdo, seja ela explícito e/ou latente" (FRANCO, 2008, p. 16).

Para as comparações contextuais, as respostas da criança foram organizadas em categorias de análise. Nesse sentido, foi levantada a categoria "Percepção da criança sobre a imagem" para as respostas das questões: 1) No que pensou para fazer esse desenho? 2) Por que você fez esse desenho? 3) Me fala sobre o filme. E, a categoria "História e significado do desenho para a criança" para as questões: 4) O que significa esse desenho para você? 5) Esse desenho conta alguma história? 6) Qual nome você dá ao desenho?

Antes de iniciar a análise de conteúdo, assisti aos filmes e as séries que a criança viu, já que se subentende que ela criou os desenhos a partir de imagens dos mesmos. Por isso, a análise realizada ao categorizar e problematizar as suas falas, faz menção aos elementos dos desenhos gráficos visualizados nos filmes ou nas séries, o que evoca o caráter da pesquisa descritiva, que é um estudo que "pretende descrever os fatos e fenômenos de determinada realidade" (SILVEIRA E CÓRDOVA, 2009, p. 35).

Por fim, a análise das escolhas temáticas nos desenhos selecionados foi de ampla relevância para a obtenção dos resultados, visto que Lowenfeld e Brittain (1977) 
contribuem para a ideia de que a vivência da criança tem repercussão na arte dela. As ideias organizadas por Lowenfeld (1976) sobre as fases de desenvolvimento da arte da criança, também colaboraram na análise realizada. Porém, esta pesquisa está mais interessada em significar as vivências da criança através dos desenhos dela, do que em pautar-se nas fases artísticas da mesma, com o objetivo de se tornar possível compreender como a criança significa os desenhos que ela cria através da visualidade de imagens cinematográficas e de séries televisivas.

\section{Análise e resultados: um pouco mais de histórias...}

\section{Percepção da criança sobre a imagem}

A criança é sujeito criador, e com base nesse pressuposto serão discutidas abordagens referentes à pergunta que este artigo caminha para responder, isso se dará à luz de teorias, dos desenhos expostos e de falas da criança a partir da entrevista. As falas trouxeram relevância para o alcance do objetivo central deste artigo que considera o dito de Derdyk (1994, p. 95) que o desenho vai receber de seu autor "uma interpretação, aliada a um comentário verbal, como se este fosse o prolongamento de sua ação".

A categoria "percepção da criança sobre a imagem" será problematizada a partir das respostas para as questões: 1) No que pensou para fazer esse desenho? 2) Por que você fez esse desenho? E, 3) Me fala sobre o filme. Contudo, é necessário esclarecer que algumas respostas para as mesmas questões foram agrupadas, pois esse agrupamento permite uma análise mais coerente e sucinta. Outro procedimento realizado considerou todos os desenhos problematizados, todavia as falas da criança que se encontram mostradas são as que aparentam proporcionar uma pertinente abordagem teórica.

"A criança enquanto desenha canta, dança, conta histórias, teatraliza, imagina, ou até silencia..." (DERDYK, 1994, p. 19). A criança é protagonista de ideias e criadora de histórias. Quando desenha, ela está expressando o que pensa e os motivos que a estimularam a produzir os desenhos. E isso aparece nas falas de Fernando José, criança que tem 11 anos e que está na Escolinha de Arte do Recife desde 2015 até o presente ano 2017. Os desenhos de Fernando que seguem, possuem os nomes que foram dados por ele durante a entrevista.

O desenho abaixo foi feito com lápis grafite e tem o nome "vulcão elétrico". Durante conversas anteriores à entrevista, Fernando falou que seus desenhos são feitos a 
partir da imaginação dele. Especificamente antes de criar o desenho "vulcão elétrico", ele assistiu alguns filmes e algumas séries que possuem dinossauros. Entre eles, foi citado o filme "Em busca do vale encantado (1988)" cujo gênero é "aventura", e a série de anime "Dinossauro Rei (2007)", de gênero ação/fiç̧ão científica. Passagens tanto do filme, quanto da série citada, aparecem através das falas dele durante a entrevista.

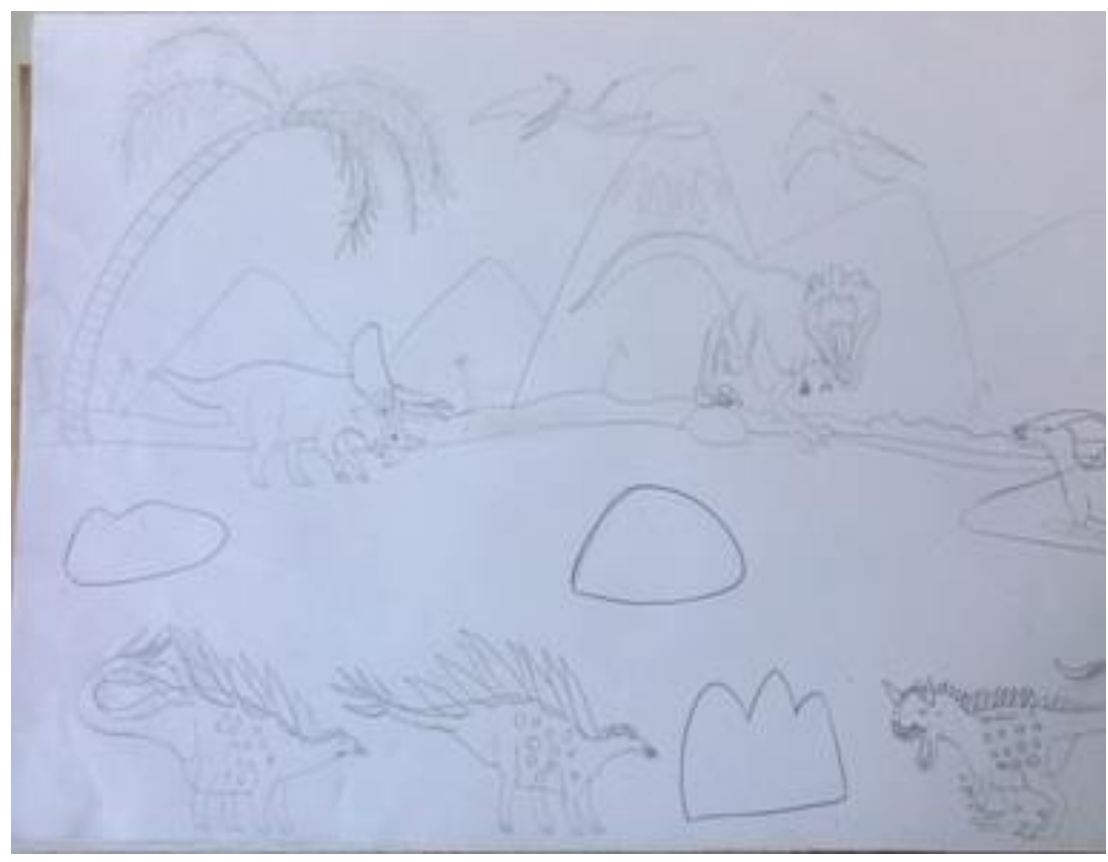

Figura 1. Vulcão Elétrico (D1) - 2017

A idade de Fernando se insere na faixa etária entre 09 a 12 anos, fase do realismo visual. Sobre isto, os autores argumentam que há "maior conscientização e interesse pelos detalhes, nesta fase de desenvolvimento, [...]" (LOWENFELD e BRITTAIN, 1977 , p. 233). Os mesmos autores afirmam que as linhas geométricas "já não são suficientes, quando o jovem se desloca no sentido de uma forma de expressão mais intimamente relacionada com a natureza" (p. 232). O desenho "vulcão elétrico" corresponde às características indicadas através das citações acima, pois no desenho não está evidenciado apego a linhas geométricas, porém, há uma representação relacionada com a natureza dos elementos desenhados, e são estes que possuem variações nas linhas e formas.

O desenho abaixo, criado através de lápis grafite e que possui o nome "monstro destruindo a cidade", representa mais uma vez o gosto de Fernando por animais 
colossais. Para criar esse desenho, Fernando fez referência ao filme Godzilla (2014) durante a entrevista, e disse que ainda finalizará esse desenho.

Godzilla é um filme de gênero "ficção científica", e o personagem Godzilla era um lagarto que fora alimentado por efeitos radioativos e se transformou num monstruoso animal que vive no oceano. Ao sair do habitat e invadir a cidade ele proporciona destruição dos elementos da cultura, como está representado no desenho.

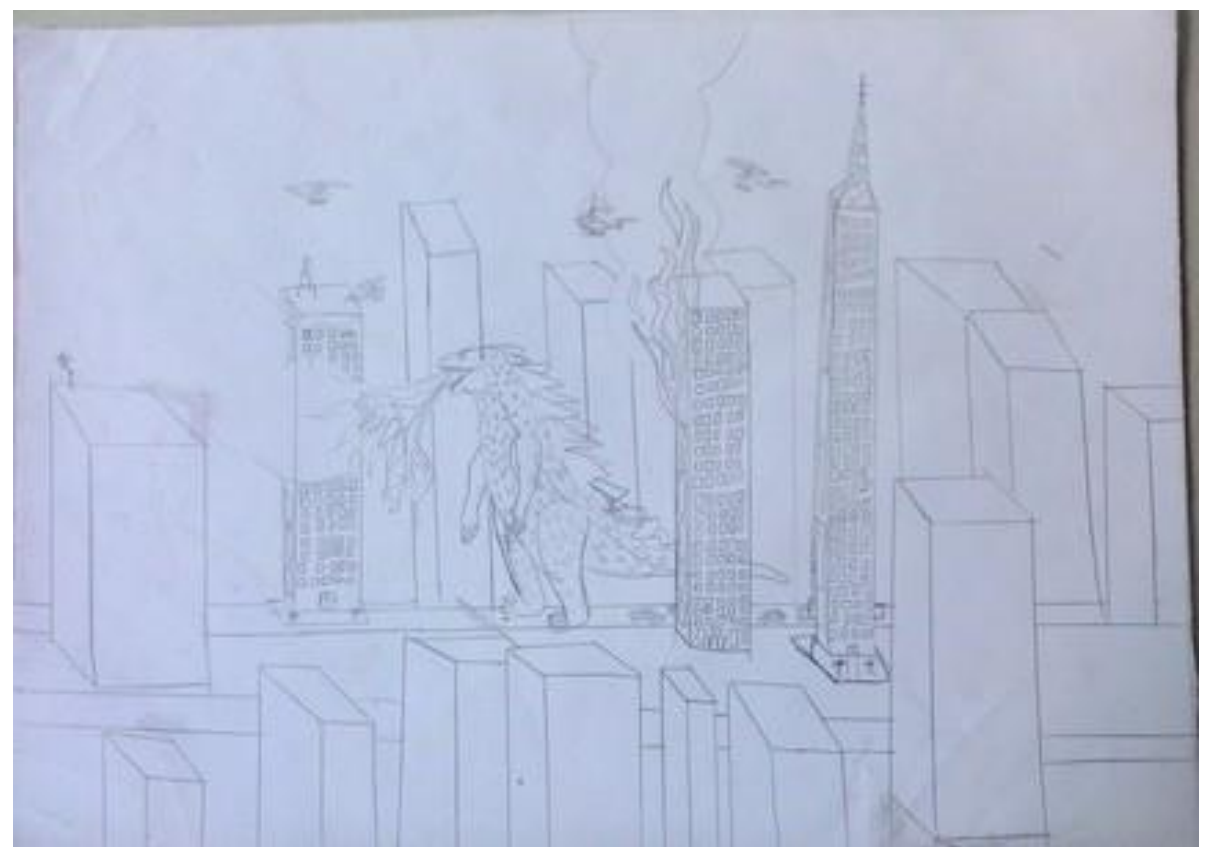

Figura 2. Monstro destruindo a cidade (D2) - 2017

Sobre as fases de desenvolvimento da arte da criança, pode-se inferir que o desenho "monstro destruindo a cidade" também se insere na fase do realismo visual, porque o mesmo denota uma conscientização do espaço visual. Conforme Lowenfeld e Brittain (1977, p. 236), como resultado dessa crescente conscientização "a criança descobre que o espaço entre as linhas de base se torna significativo, e o plano é também descoberto".

Durante a entrevista, ao ser perguntado à criança no que pensou para fazer os desenhos vulcão elétrico (D1) e monstro destruindo a cidade (D2), foram obtidas as respostas:

Que antigamente, na época que não existia gente, bem existia, pouca gente. Na época dos dinossauros, mas não é história. Bem é história do tempo dos dinossauros que eu 
inventei. Ah, tem também uma história que eu fiz vários dinossauros, só um com cara de dinossauro, todas as caras de dinossauros com papéis pequenos, [uma técnica artística] desse tamanho...! Era a história do meteoro, de dinossauro meteoro que eu inventei um boneco (D1).

Na verdade eu inventei um mostro destruindo a cidade. Ele é o Godzilla, e eu não sabia que ele era o Godzilla não, que não dá pra ver de trás, só dá pra ver ele olhando pra pessoa, assim ó, botando ele pra cá, cabeça pra cá fica parecendo um gorila, um gorila misturado com um lagarto [Fernando explica apontando para a cabeça de Godzilla] (D2).

Fernando fala em ambas as respostas sobre a invenção de histórias, isso está relacionado ao potencial criativo dele como uma pessoa que constrói e reconstrói histórias. Sobre a relação da pessoa com a história, Derdyk (1994, p. 18) argumenta que "a história pode ser feita a todo momento: o homem é seu grande inventor e sua grande invenção". Como um inventor, Fernando faz referência no desenho 1 ao período de existência dos dinossauros como um período histórico.

Quando perguntado o porquê dele ter feito os desenhos 1 e 2, Fernando respondeu:

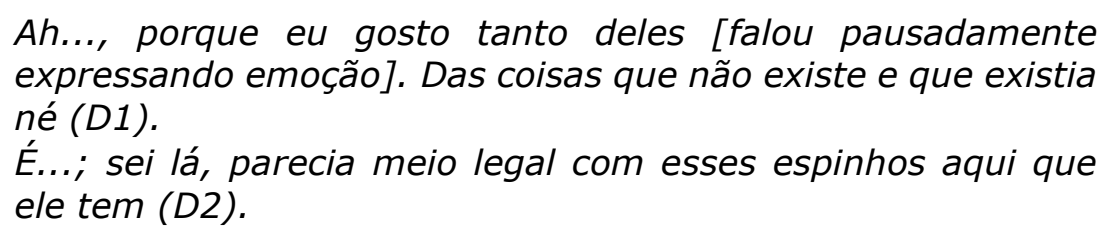

"Não há expressão artística possível sem auto-identificação com a experiência revelada, assim como com o material artístico utilizado para esse fim" (LOWENFELD e BRITTAIN, 1977, p. 28). As repostas da criança para a pergunta referida revelam a expressão do eu como motivo para a criação dos mesmos. Além do todo falado, os fragmentos falados "eu gosto tanto deles" e "meio legal" demonstram isso.

O desenho abaixo recebeu o nome "terra terrestre". Ele foi desenhado com lápis grafite e colorido com lápis madeira de cores variadas. 


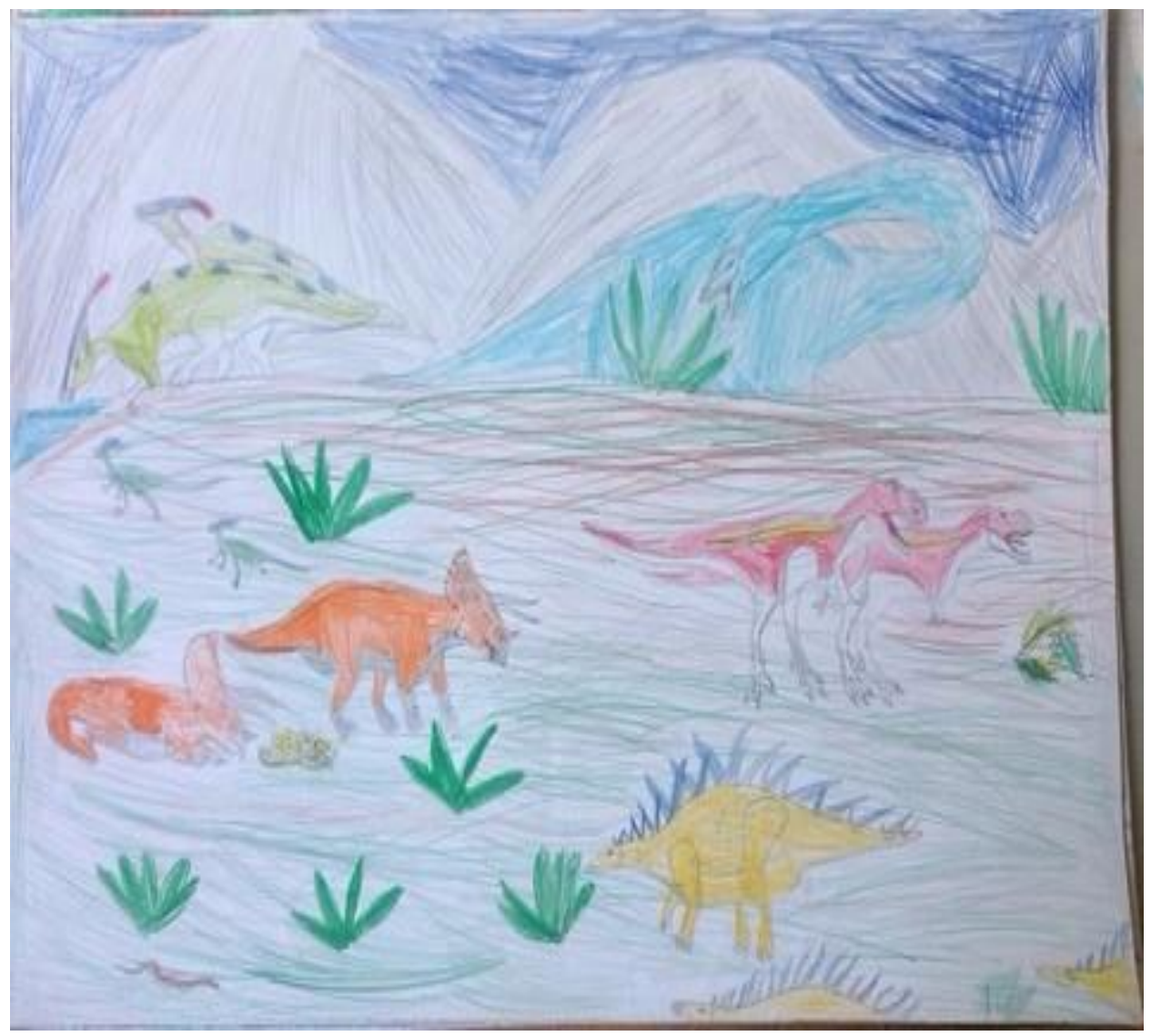

Figura 3.

Terra terrestre (D3) - 2017

Esse é mais um desenho que demonstra o gostar de Fernando por dinossauros. Antes de criar este desenho, ele assistiu ao filme "Em busca do vale encantado (1988)", e a série de anime "Dinossauro Rei (2007)". Nesse desenho está expresso o aproveitamento das linhas de base e do plano espacial, com o uso de variadas formas e de dimensões de espacialidade.

Quando foi solicitado a Fernando para que falasse sobre os filmes referentes aos desenhos vulcão elétrico (D1), monstro destruindo a cidade (D2) e terra terrestre (D3), ele respondeu:

Tem do boneco Littlefoot. Tem do, ah... Como é aquele mesmo? [tentou lembrar]. Dinossauro Rei, daquele boneco que tem a carta... também vi um filme mais nada, só aqueles mesmos. [Fernando se referiu ao filme: Em busca do Vale encantado, e, a série: Dinossauro Rei] (D1)

Me lembro não, foi quando eu era pequeno [Fernando fez referência ao filme Godzilla]. (D2)

Só que a mãe de Littlefoot, daquele bonequinho [Littlefoot] já foi morta. E ai ele só ficava agora com os avôs dele. (D3) 
A memória de Fernando é categórica no que tange às suas falas, e essas memórias indicam os sentimentos dele perante os filmes e as séries que foram assistidas e perante os desenhos criados. Nesse sentido, há uma apropriação de ideias, isto está em sintonia de que "desenhar [...] situações, animais, emoções, ideias são tentativas de aproximação com o mundo. Desenhar é conhecer, é apropriar-se" (DERDYK, 1994, p. 24).

O desenho abaixo que recebeu o nome "infantis", foi desenhado com lápis grafite e colorido com giz de cera com cores variadas. Nele contém os personagens Julieta e Romeu do filme que pode ser chamado pelo nome "Alpha e Omega" ou "A lady e o lobo: o bicho tá solto" (2010), gênero comédia/romance.

No enredo do filme esses personagens citados estão entre os principais protagonistas, e em uma parte da história Julieta e Romeu se apaixonam, porém eles têm o impedimento de ficarem juntos por terem características distintas, além do Alpha ser considerado superior ao Ômega. No entanto, no final do filme a barreira é vencida e a Alcateia é unida através do casamento de Julieta e Romeu. O casamento deles é citado por Fernando ao falar sobre o desenho.

O desenho é uma criação de Fernando e não uma cópia de alguma cena do filme. Nele é explorado o espaço do papel indo além das formas geométricas, foi criado com o uso de linhas com distintas espessuras, e, por ele utilizar diferentes formas, esse desenho é multiforme. Nas cores dos personagens fez contrastes entre tons claros e escuros, relevando a livre expressão e os conhecimentos que possui. Isso remete à ideia de que a fase do desenvolvimento da arte de Fernando é o realismo visual, levando em conta os escritos de Lowenfeld e Brittain (1997) sobre essa fase. 


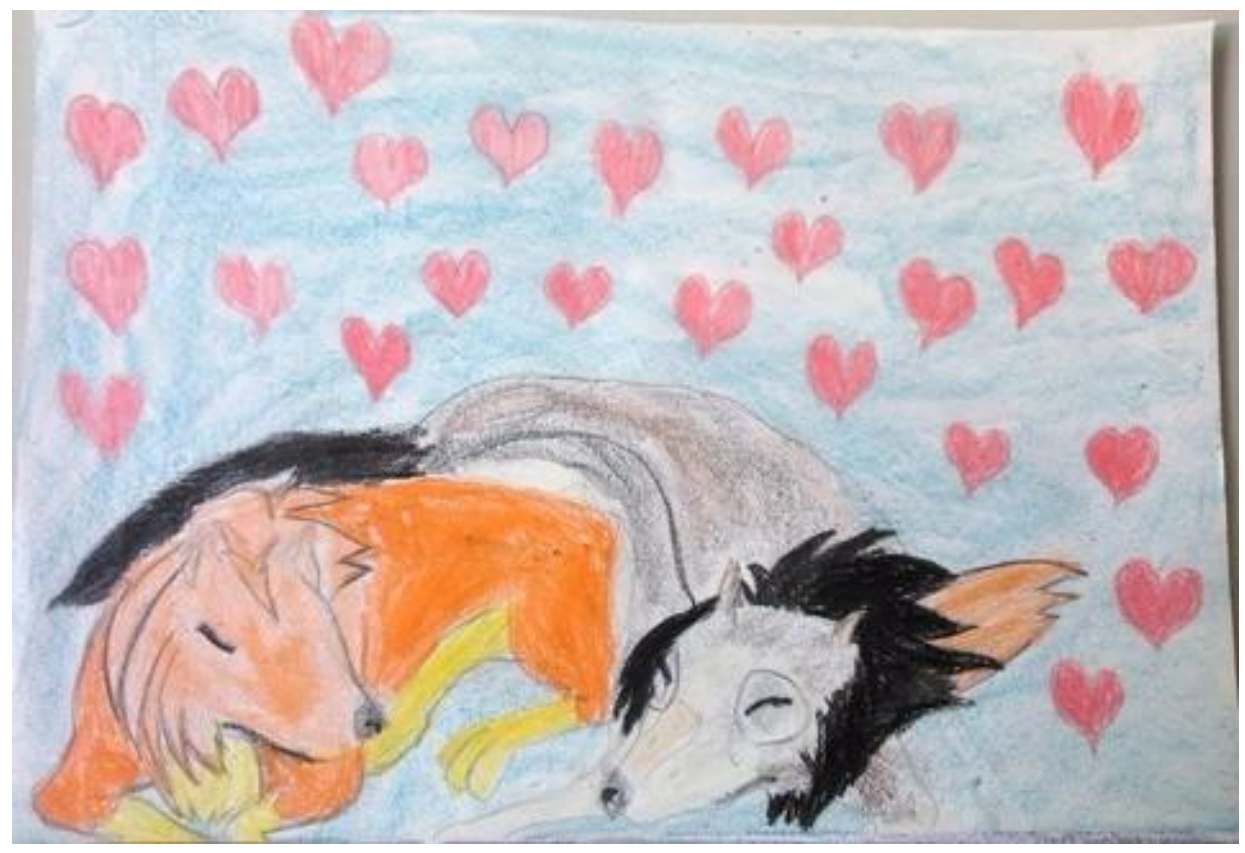

Figura 4. Infantis (D4) - 2017

O próximo desenho com o nome "golf" foi produzido com lápis grafite, coberto com canetas hidrográficas e pintado com lápis coloridos de madeira em variadas cores. Nesse desenho contém personagens do filme Kung Fu Panda, o que foi confirmado a partir das respostas durante a entrevista.

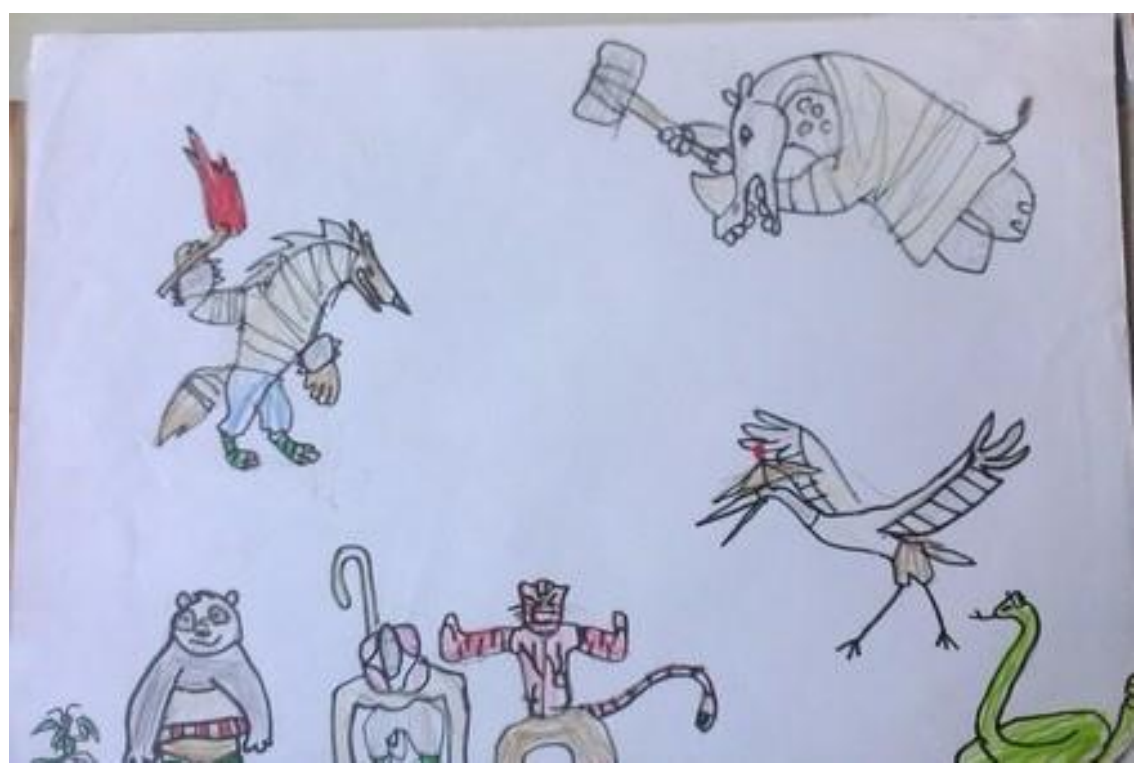

Figura 5.

Golf (D5) - 2017

O gênero desse filme é animação/aventura, o mesmo existe nas versões 1, 2 e 3, e em todos os lançamentos o Panda, personagem "Po" é o principal protagonista porque ele foi escolhido para ser o Mestre dos guerreiros da China e com o auxílio 
dos guerreiros (alguns outros personagens que estão no desenho), o Panda consegue manter a paz no Vale, lutando contra os invasores.

Esse desenho é uma criação de Fernando, pois não há cenas em um dos filmes Kung Fu Panda em que todos os personagens estão agrupados da forma representada no desenho gráfico. A ideia de desenho como uma criação lembra o que Derdyk (1994, p. 112) diz sobre o desenho: "É sempre uma interpretação, elaborando correspondências, relacionando, simbolizando, significando, atribuindo novas configurações ao original".

Ao ser solicitado para que Fernando falasse sobre os filmes que o inspiraram a fazer os desenhos infantis (D4) e golf (D5), ele disse:

Que eles estavam se casando lá numa pedra onde o lobo fica de noite na lua cheia. [Ele referenciou o filme: A lady e o lobo: o bicho tá solto] (D4)

Ele [um dos personagens do desenho gráfico] lutando com um bando de macaco e andando sozinho, ainda mais tem uma ladeira, ainda mais de uns cagarros e depois eles caíram numa sombrinha. Ele [personagem citado anteriormente] é um tipo de pavão mal. [Referência ao filme Kung Fu Panda] (D5)

"A criança, ao se tornar intérprete de seu próprio desenho, demonstra o seu potencial de criar significações, num jogo contínuo entre o real, o percebido e o imaginário" (DERDYK, 1994, p. 98). As falas de Fernando parecem demonstrar uma relação entre o que ele viu e o que ele quis representar em desenhos gráficos a partir do próprio potencial de imaginar e criar, pois, apesar dele se referir a casamento ao falar sobre o desenho 4 (D4), os personagens não foram representados se casando, e, no desenho 5 (D5) não aparece o bando de macacos que ele citou ao falar, por exemplo. Nesse sentido, criar é significar as imagens do mundo.

\section{História e significado do desenho para a criança}

A categoria em questão se constitui um diálogo com o que foi problematizado na categoria anterior, tendo em vista que a criança é sujeito capaz de criar histórias a partir das representações gráficas e a partir da própria fala. Por isso, é relevante considerar que "a palavra pode transformar o rabisco, o signo gráfico, numa personagem capaz de narrar estórias" (DERDYK, 1994, p. 98). 
Em atenção a esta categoria, as respostas analisadas foram: 4) O que significa esse desenho para você? 5) Esse desenho conta alguma história? Referente à pergunta número 6 (qual nome você dá ao desenho?), foi feita em reconhecimento à importância de criação da criança e para que os desenhos ganhem mais vida através de nomes próprios.

Assim, ao ser questionado sobre o que significam para ele os desenhos vulcão elétrico (D1), mostro destruindo a cidade (D2) e terra terrestre (D3), Fernando respondeu:

Vou olhar, acho que não sei não... Acho que ele é importante, mas não sei dizer. (D1)

Ah... Que algo aconteceu, alguma coisa, um monstro sobreviveu dos dinossauros. Ele existia na época dos dinossauros, só que ele era nem do tamanho de um pescoço alto. (D2)

Acho que significa que eu gosto tanto. (D3)

As falas da criança demonstram que ela se identifica com os trabalhos artísticos que produziu, cria desenhos com motivações, os cria porque estes possuem algum significado que se relaciona com a pessoalidade dela. Criar é uma atividade educativa porque envolve imaginação, afetividade e exaltação de prazer, além de ser uma habilidade humana sempre em desenvolvimento. Sobre a criação artística de crianças, Lowenfeld e Brittain (1977, p. 48) dizem: "As crianças não precisam ser habilidosas para serem criadoras, [...].".

Ao ser perguntado se os desenhos terra terrestre (D2), monstro destruindo a cidade (D3) e golf (D5) contam alguma história, ele respondeu:

Eu acho que ele conta alguma história que eu vi. Lá no terreno tem águia lá, uma águia que só dá pra ver o [eu não entendi a palavra], águia mais ou menos, lá tem águia, lá. No terreno onde eu moro, lá tem cagarro, tem urubu, tem águia, tem preá. (D2)

Não. Os dinossauros não existem no acontecimento, bem, já existia cidade na época dos dinossauros, mas eram pouquinhas pessoas. Não sei quantas, mas parece que era um ninho de pessoas numa pequena cidade que só tem um ninho de casas. Também tem alguma coisa pra ver os bichos, os lagartos passar, sabe, os dinossauros. (D3)

Não. Ah, tem também uma vez que eu desenhei um pica-pau aqui, eles jogando um copo né? (D5) 
As respostas de Fernando revelam a interpretação dele a respeito da palavra história. A resposta para o desenho 2 (monstro destruindo a cidade) revela uma aproximação com a história pessoal dele na interpretação do desenho. Isto caracteriza que a história pessoal dele junto aos animais que ele conhece e tem contato, possui significado para ele, e por isso entende como "história" esses momentos vividos. No tocante ao desenho 5 (golf), a ação do pica-pau sendo lembrada como uma história para o D5, também reflete o potencial imaginativo dele, um momento que ele viveu e talvez o fato de ter assistido o desenho animado Pica-pau.

Sobre a história para o desenho 3 (terra terrestre), Fernando falou sobre o período de existência dos dinossauros com uma resposta que pode indicar o que de fato ele acredita que aconteceu, ou ser para ele como uma "estória", ou seja, um conto inventado e que faz todo o sentido para ele. Se Derdyk (1994, p. 18) escreveu: "A história pode se fazer a todo o momento: o homem é seu grande inventor e sua grande invenção"; a criança como um sujeito inventor pode inventar estórias ou interpretar fatos históricos da forma que deseja, tendo como ponto de partida as histórias que ela vive ou que ela conhece.

Os desenhos de Fernando apresentados neste trabalho foram produzidos na Escolinha de Arte do Recife, como já dito anteriormente. Esses desenhos são resultado dos conhecimentos desta criança que está em um espaço em que os/as professores/as trabalham com a arte de forma inclusiva, numa metodologia baseada na perspectiva pós-moderna "arte como conhecimento" através de um trabalho que aproveita os saberes artísticos e socioculturais das crianças e as deixam criar, ler e contextualizar os trabalhos artísticos.

Sobre a EAR, Silva e Moser (2013), se aproximam a partir dos nortes metodológicos desta, ao dizer que desde a sua fundação em 1953, a escolinha aspirava a capacidade criadora bem como o desenvolvimento integral da individualidade infantil, tendo sido o espaço onde as pessoas buscavam um princípio pioneiro de ensino através da arte. Atualmente a EAR continua trabalhando com essa perspectiva, o que foi possível observar a partir das minhas idas à escolinha, também se percebeu que existe um trabalho de valorização da livre expressão das crianças em diálogo com a perspectiva de arte como conhecimento. Isto demonstra que a EAR é uma instituição histórica 
que preza pela arte, cujo estilo se faz presente nos expressivos e históricos desenhos de Fernando.

\section{Considerações finais}

Este artigo, em face ao protagonismo adotado, buscou compreender como a criança significa os desenhos gráficos criados por ela através da visualidade de imagens cinematográficas e de séries televisivas. Inicialmente, antes de Fernando ser entrevistado, além dos desenhos, as imagens cinematográficas seriam objeto de estudo, decisão tomada após conversas com ele. Porém, após a entrevista, ficou evidente que séries televisivas também o influenciaram, de alguma forma, em alguns dos desenhos.

O fato acima, revela as significantes aprendizagens que o pesquisador pode construir através do contato com os sujeitos da pesquisa, e revela, também, que aprender é um processo em aberto. Destarte, os objetivos da pesquisa revelam a partir da categoria 1 "percepção da criança sobre a imagem", que Fernando falou sobre o gostar dele por animais colossais, entre eles, os dinossauros (ele conhece os nomes de espécies), inspiração marcante para desenhar esses animais. O gostar desenvolvido por animais colossais é demonstrado através dos desenhos vulcão elétrico, monstro destruindo a cidade, e terra terrestre.

Fernando também se revelou um contador e criador de histórias ao falar sobre Godzilla e sobre os dinossauros. Isto é evidenciado quando disse que inventou um monstro destruindo a cidade e falou como fez o Godzilla, e ao falar como era o período em que os dinossauros viveram. E ao falar sobre o período em que os dinossauros viveram, demonstra sua capacidade interpretativa para fatos históricos e/ou criou histórias. Outra questão relevante é que os desenhos que faz, são criações, mesmo tendo relação entre os desenhos com momentos de filmes e de séries de TV.

A expressão do eu de Fernando aparece como significado para as criações, considerando que sua narrativa sobre os filmes e séries assistidas, não foram necessariamente o que ele desenhou. A própria criança falou que criou/inventou os desenhos, e os resultados apontam que ele significou as reproduções quando criou os desenhos a partir de suas memórias. Isto pode ser constatado quando fala sobre o filme "A lady e o lobo", ao dizer que os personagens que foram desenhados estavam

Revista Digital do LAV - Santa Maria - vol. 10, n. 3, p. 73-97 - set./dez. 2017 ISSN 1983 - 7348 http://dx.doi.org/10.5902/1983734828861 
se casando no filme, ou seja, foi uma cena marcante para ele, porém não expressou no desenho a cena do casamento que aparece no filme.

Referente à categoria 2 "história e significado do desenho para a criança", os resultados indicam que os desenhos do Fernando significam acontecimentos e ainda a auto identificação dele com o que foi desenhado. Algumas respostas revelaram que a história que esses desenhos contam, estão relacionadas à sua história pessoal, por exemplo, ao falar sobre o desenho "monstro destruindo a cidade" conta que no terreno que ele mora tem animais diferentes. Também fez relação da história que o desenho 5 "golf" mostra, com um desenho que fez de um pica-pau, ou seja, provavelmente um desenho que ele gostou de fazer em um momento da vida dele.

Tudo isto mostra que Fernando significa os desenhos criados por ele como desenhos que revelam o gostar dele por animais e 'contam' histórias que remetem à vida dele. Fica evidenciado que os filmes e as séries influenciaram na produção dos seus desenhos, ao falar sobre cenas vistas a partir dessas tecnologias audiovisuais e culturais. Todavia, a história, a imaginação e a criatividade de Fernando se sobressaem na significação que ele atribuiu aos desenhos criados por ele. Este aspecto chama a atenção para que os profissionais, sobretudo, da educação, acreditem no potencial criador da criança cuja história de vida figura como um contributo no compartilhamento de conhecimentos.

\section{Referências}

AUMONT, J. A parte do olho. In: (org.). A imagem. 7a edição. Campinas:
Papirus, 2002.
Cap.
01.
Disponível
em: https://ayrtonbecalle.files.wordpress.com/2015/07/aumont-jacques-a-imagem.pdf. Acesso em: 14/05/2017, às 13:40.

AZEVEDO, F. A. G. de. Movimento Escolinhas de Arte: em cena memórias de Noêmia Varela e Ana Mae Barbosa. In: BARBOSA, A. M. (Org.). Ensino da arte: memória e história. São Paulo: Perspectiva, 2011. Cap. 09.

BARBOSA, A. M. A imagem no ensino da arte: anos oitenta e novos tempos. $6^{a}$ ed. São Paulo: Perspectiva, 2005. 
As exposições infantis: modernismo e culturalismo. In: BARBOSA, A. M. (Org.). Redesenhando o desenho: educadores, política e história. São Paulo: Cortez Editora, 2015. Cap. 10.

Dos preconceitos contra o ensino da arte: revisão do século XIX. In:

(Org.). Arte-Educação no Brasil. 6. ed. São Paulo: Perspectiva, 2010. Cap. 01. Inícios do século XX: Realizações das propostas oitocentista e influência americana. In: BARBOSA, A. M. (Org.). Arte-Educação no Brasil. 6. ed. São Paulo: Perspectiva, 2010. Cap. 02.

DERDYK, E. In: Formas de pensar o desenho: desenvolvimento do grafismo infantil. 2. ed. São Paulo: Scipione, 1994.

ESCOLINHA DE ARTE DO RECIFE. Breve notícia sobre a Escolinha de Arte do Recife. (sem indicação de ano). Recife. Documento informativo. Declarada de utilidade pública Federal, pelo decreto no 92.921, de 11.07.1986.

FANTIN, M. Cinema e imaginário infantil: a mediação entre o visível e o invisível. Revista Educação \& Realidade, Porto Alegre, UFRGS, 34 (2) p. 205-223, mai./ago., 2009. Disponível em: file://C:/Users/Maisa/Downloads/9357-31156-1PB\%20(2).pdf. Acesso em: 14/05/2017, às 14 hrs.

. Cinema, televisão e participação estética. In: Crianças, cinema e mídia-educação: olhares e experiências no Brasil e na Itália. Tese (Doutorado em Educação) - Programa de Pós-Graduação em Educação, Universidade Federal de Santa Catarina, Florianópolis, 2006a. Cap. 01. Disponível em: http://livros01.livrosgratis.com.br/cp054095.pdf. Acesso em: 14/05/2017, às 13 hrs.

FRANCO, M. L. P. B. Análise de conteúdo. 3 ed. Brasília: Liber Livro Editora, 2008. FRASER, M. T.; GONDIM, S. M. Da fala do outro ao texto negociado: discussões sobre a entrevista na pesquisa qualitativa. Paidéia, Bahia, UFBA, 14 (28), p. 139-152, 2004. Disponível em: http://www.scielo.br/pdf/paideia/v14n28/04.pdf/. Acesso em $10 / 06 / 2017$, às 11 hrs.

Revista Digital do LAV - Santa Maria - vol. 10, n. 3, p. 73-97 - set./dez. 2017 ISSN 1983 - 7348 http://dx.doi.org/10.5902/1983734828861 
LOWENFELD, V.; BRITTAIN, W. L. Desenvolvimento da capacidade criadora. São Paulo: Editora Mestre Jou, 1977.

LOWENFELD, V. A criança e sua arte. São Paulo: Mestre Jou, 1976.

MAZZOTTI, A. J. A. O Planejamento de pesquisas qualitativas. In: MAZZOTTI, A. J. A.; GEWANDSZNAJDER, F. (Orgs.). O Método nas Ciências Naturais e Sociais: Pesquisa Quantitativa e Qualitativa. São Paulo: Pioneira, 2011. Cap. 07.

RIZZI, M. C. Reflexões sobre a abordagem triangular do ensino da arte. In: BARBOSA, A. M. (Org.). Ensino da arte: memória e história. São Paulo: Perspectiva, 2011. Cap. 09.

SILVA, E. M. A. Arte/Educação e conhecimento: por uma nova epistemologia do Ensino da Arte na Educação Escolar. In: Arte como conhecimento: as concepções de ensino de arte na formação continuada dos professores dos anos iniciais do Ensino Fundamental de Recife. 2005. Dissertação (Mestrado em Educação). Programa de Pós-Graduação em Educação. Universidade Federal de Pernambuco - UFPE, Recife. Cap. 01.

SILVA, M. V. B. Cultura das séries: forma, contexto e consumo de ficção seriada na contemporaneidade. Galaxia (São Paulo, Online), n. 27, p. 241-252, jun. 2014. Disponível em: http://dx.doi.org/10.1590/1982-25542014115810. Acesso em: $28 / 05 / 2017$, às 14 hrs.

SILVA, M. B. e; SANTOS, A. P.; AZEVEDO, M. L. Memórias não são só memórias: A Escolinha de Arte do Recife (1953-2013). Recife: Editora Universitária da UFPE, 2013.

SILVEIRA, D. T.; CÓRDOVA, F. P. A pesquisa científica. In: GERHARDT, T. E.; SILVEIRA, D. T. (Orgs.). Métodos de pesquisa. Porto Alegre: Editora da UFRGS, 2009. Cap. 2. p. 31-42. Disponível em: http://www.ufrgs.br/cursopgdr/downloadsSerie/derad005.pdf. Acesso em: $13 / 01 / 2017$, às 12 hrs. 
WILSON, B.; WILSON. M. Uma Visão Iconoclasta das Fontes de Imagem nos Desenhos de Crianças. In: BARBOSA, A. M. (Org.). Arte-Educação: leitura no subsolo. 8. ed. São Paulo: Cortez, 2011. p. 59-77.

' Curso Pedagogia no Centro de Educação da Universidade Federal de Pernambuco (2017.2). Monitoria acadêmica e, atualmente, eu participo do Programa de Iniciação a docência (PIBID/CAPES/UFPE) no subprojeto Pedagogia/História. Artigos na área Étnicorracial e me interesso por pesquisas no âmbito da subjetividade infantil com o objetivo de escutar as vozes de crianças.

ii Doutora em Ciências da Educação pela Universidade do Porto - Portugal. Professora Associado 1 na Universidade Federal de Pernambuco do Departamento de Administração Escolar e Planejamento Educacional.

Como citar esse artigo:

SOBRAL, Maísa Gomes; BARBOSA, Márcia Regina. Os desenhos de uma criança da Escolinha de Arte do Recife: o olhar artístico em meio às imagens cinematográficas e às séries televisivas. Revista Digital do LAV, Santa Maria: UFSM, v. 10, n. 3, p. 73-97, set./dez. 2017.

Enviado em: 31 de agosto de 2017.

Aprovado em: 07 de dezembro de 2017. 